\title{
The Reform and Practice of Architectural Teaching System in Local Universities under the Background of Energy Conservation
}

\author{
Bai Ling ZHOU ${ }^{1, a}$, Jun $\mathrm{YE}^{2}$ and En Tian $\mathrm{QIE}^{3}$ \\ ${ }^{123}$ College of Urban Construction, Wuhan University of Science and Technology, Wuhan, Hubei 430065, P.R. China
}

\begin{abstract}
In order to realize the diversification and differentiation development of architecture professional teaching in local universities under the background of energy conservation, we must scientifically determine the training objectives, arrange reasonable relevant courses, adjust to enrich teaching contents, and continuously enrich the teaching methods. Thus we will form professional framework adapting to the development of local, which reflects the different characteristics of architectural specialty.
\end{abstract}

\section{Introduction}

On the whole, Chinese modern architectural education began in 1927, which founded.in National Central University (Southeast University now). Since then, there were only a dozen universities that set up the department of architecture in the whole country during the course of more than half a century. It seemed that architecture had become a veritable "noble" discipline from then on. Since the reform and opening up of China in the 1980's, the architectural speciality of our country's colleges and universities has made a rapid progress. There are over 220 universities which have set up architecture department by the end of the year 2012. And 75 of them have put on record in department of personnel and education in Ministry of construction, 35 of them have passed the evaluation of authorizing bachelors degree of architectural education.

On one other hand, the academism of Europe and the United States which is represented by Germany Bauhaus and Russian Bxytemac has a profound influence in contemporary Chinese architectural education system. On the other hand, China is facing a historical period of transition from developing country to developed country at present. With the rapid advance of the urbanization process, some natural villages on the edge of city have gradually developed into towns and towns have gradually developed into the city, which causes a great demand for talents of urban planning and architecture. Due to the social economic system in China has been transferred from planned economy to market economy, the "uniform" professional teaching mode of the past has significantly lagged behind the current situation of economic and social development.
All though in recent years, various colleges and universities have tried to adjust the educational system which is relatively closed and conservative, but there is no change in the overall breakthrough. For example, how to adapt the architecture departments of local colleges and universities to the development of society? How to research and practice in line with its own characteristics of the architectural education model according to local conditions with a clear mind? How to deal with variety of negative issues such as their relatively blurry positioning and the indistinct objectives of their talent cultivation.

Different levels of colleges and universities should have different training objectives. At the beginning of the founding of new China there were eight schools in architectural education which were first to offer urban planning or architecture departments in college, including Tsinghua University, Southeast University, Tianjin University, Tongji University, Harbin University of Architecture (now Harbin Institute of Technology), South China University, Chongqing Architecture University (now Chongqing University) and Xi'an Metallurgical Construction Institute (now Xi'an University of Architecture and Technology). The latterly four schools were to balance the layout of architecture education in various regions of the country in the wave of adjusting disciplines in PRC in 1952. The formerly institutions possess powerful teachers and long academic lineage (mainly inherited in the United States, Europe and Japan).

These eight schools constitute the first echelon of the professional education of architecture in our country, which have trained a large number of professionals in the architecture of high-end talent since the beginning of the establishment, making a great contribution to the

\footnotetext{
${ }^{\mathrm{a}}$ Corresponding author: cps.zhou@gmail.com
} 
economic development of our country. Up to now, International professionals with innovative spirit and professional leaders are still the orientation of their talent training objectives.

Since China's reform and opening up in 1979, China's higher education has been greatly changed. So far we have formed the structure of the three modes coexist: the national "211 Project" universities, universities co-established by the province and the ministry, local colleges and universities. Most of the local colleges and universities (provincial universities) rely on local financial support, which are allocated funds from local administrative departments. They aim to serve the economic and social development of the region and strive to cultivate high quality talents. Since local college students and graduates employment whereabouts are with obvious regional color, the Architectural Education in these colleges should take the main goal of training local talents as the main goal of running a school.

\section{Current Situation}

The architecture departments in local universities have much in common with Chinese famous universities from all aspects, such as talent cultivation target approximation, syllabus convergence, curriculum setting, and the teaching method and so on. The Architectural Education in local colleges and universities has a few disadvantages, such as obsolescence of teaching system, lack of engineering application and innovation ability, which cannot meet the needs of local social and economic development. In addition, they are lack of policy and law guarantee, special funds to support. That the insufficient internal demand of design enterprise in college-enterprise joint cultivation led to that the connection between school and enterprise is not close enough. Some problems are particularly prominent, such as the gap between higher engineering education and the demand of talent market. Therefore, we must establish the architectural profession education system which attaches importance to the training of engineering application and innovation ability, strengthens the training of employment and Entrepreneurship, and then we can develop applied excellent engineers to meet the needs of the community.

At present, the architecture specialty course in Engineering University in China is mainly composed of 4 modules: the design course module whit architectural design, planning and design, landscape design and so on as the core; technical course modules represented by building structures, building equipment, construction technology, materials and construction courses; the architectural theory curriculum module represented by architectural history; the performance of the class module based on art training and computer software teaching.

This kind of course generally uses the teaching method of classroom teaching, adding the drawings or exercises to practice. The duck-feeding mode makes the students are no sense of developing innovative ideas.
They are lack of proactive creative thinking, only accepting the knowledge passively. For example, the teaching thought of the course of building structure is still a continuation of the teaching thinking of the students of civil engineering, and focuses too much on the derivation of the formula for the calculation of mechanics and structure, which ignores the demand for technology integrated design innovation capability in the course of the architect's practice. The courses of construction technology and materials are obviously lack of comprehensive training content.

"The first rule is academic history" is a sentence we often speak of, which shows the importance of professional history in various disciplines. The level of mastering architectural history (Theory) determines the extent of the students' vision, which deeply influences students' professional development in the future.

But the relative lack of the books in the history of architecture, especially in the architectural criticism, has made many students is inadequacy in the accumulation of architectural theory. The theoretical study or discussion of undergraduate students in professional learning is almost a blank in the existing architecture teaching system in our country, whether it is in science and engineering or Art College. A considerable part of the students' understanding of the building are often equated with the copy of surface form or function. Although their conversations buzzed with talk of "high tech" and "minimalism", but they do not know what it is, where it is produced from, what is the meaning of existence?

Generally speaking, most colleges and universities have chosen to arrange the design course and practice according to the building type. First grade arrangements for basic and architectural art courses; thereafter the second grade to the fifth grade, each semester has a plurality of different types of architectural design project from the shallow to the deep, through simple function to complex functions. The first is a reading room, small restaurants, independent residential, kindergarten and then to the club, museums, office buildings, hotels, theaters, and so on. It is very difficult to understand all aspects of building design only through a few limited building types. These conditions cause the serious gap between the professional education and the engineering practice become bigger and bigger.

18 weeks of practice Design Institute in the current architecture teaching syllabus of our country is shorter than any other country. At the same time the architects of Design Institute have no defects in the guidance of the students of architecture department because of the pressure of their own business. This caused most of the students' training project is just going through the motions, which didn't play a real role at all. The section headings are in boldface capital and lowercase letters. Second level headings are typed as part of the succeeding paragraph (like the subsection heading of this paragraph).

\section{Reform Ideas}


From the professional teaching goals, the architecture school's professional education must help the students to establish the correct concept of architecture by understanding the relationship between cultural property and engineering property of architecture, so that they will deeply understand the social, economic, technical and other factors which the architectural design constraints. Let them understand the experience of a large number of complex and detailed work procedures of a building from conceptual design to the final completion. So as to improve the comprehensive ability of students.

From the point of view of curriculum, we must adhere to the base of enhancing the comprehensive ability and improving the overall quality. We integrate the traditional basic course module, the design module, the technical course module, the teaching arrangement of the theoretical course module together by updating the content of technical courses, strengthening the horizontal connection of technical courses and design courses, exploring new curriculum outline. So as to form a new teaching link and mode. We will enrich the new knowledge, theory and technology to the teaching content, and provide students with the teaching content in line with the needs of the times.

We set up a number of main courses to break through the single course model which takes the architectural design as the main. These series of courses are relying on each other, from easy to difficult, step by step, which highlight the building energy saving, environmental protection and other emerging technologies.

In terms of specific methods, we put forward the teaching method of architecture specialty based on the integration principle of art and technology. The reform and practice of curriculum system construction consists of three aspects in order to achieve the ideal teaching purpose: the integrity of the teaching organization, the continuity of the teaching process and the dynamic evaluation of the teaching process.

We carry out architectural teaching activity on the integration principle of art and technology by taking the architectural design courses as a link and taking the conceptual design as the center. In the course, we combine architecture design with structure design, power design, water supply and drainage design, HVAC design, paying particular attention to fire protection design and environmental landscape design. In the process of integrated design, we take the apprenticeship model (teacher - student): Each tutor and student carries out two-way choice according to their interests and study direction. Determine the respective design issues and optimize the teaching process on the basis of the full discussion. We do will all flowers bloom together. We should also pay attention to the communication between teachers and students, especially among the instructors.

We broke the parallel state of each technologic curriculum in the traditional teaching mode. We closely integrated multi courses such as building design principle, building structure selection, architectural physics (sound, light and heat), and building tectonic, building security by taking the student's design blueprint in design course module as the core. We open up the original system of the lack of coordination of different knowledge finally.

We highlight the core status of the architectural design curriculum module by integrating the teaching process of program, technology and art. The teachers of the relevant courses arrangement unit training session surrounding the drawings of architectural design course module of last term or this term on the basis of the theory. We will eventually build the architectural design module drawings as an important indicator of the expiration of the assessment, which have completely abandoned the traditional evaluation system (Usually work adds final examination). That prevents students being great at rote memorization, but ill-prepared for creating progress and change in the world.

\section{Conclusions}

With the rapid economic development in China, more and more energy is consumed for the improvement of people's living conditions. The building sector accounts for $33.32 \%$ of Chinese energy requirements currently, which was only $15 \%$ in 1992 and $27.45 \%$ in 2004. In particular, residential buildings represent nearly $61 \%$ of the total energy consumption in the building sector. Furthermore, $\mathrm{CO}_{2}$ emissions from residential buildings are the fifth largest key source of greenhouse gas emissions in China. They accounted for $12 \%$ of total greenhouse gas emissions in 2010. Significant potential exists to reduce the rate of future gas emissions in the building sector by promoting energy efficiency in buildings.

The opening words of the citation when Zaha Hadid was named as the first woman to win the prestigious Pritzker Prize for architecture in 2004 were: "Her architectural career has not been traditional or easy." You could call her work baroque modernism. Baroque classicists like Borromini shattered Renaissance ideas of a single viewpoint perspective in favour of dizzying spaces designed to lift the eyes and the heart to God.

Modern citizens need aesthetic appreciation from architecture so that they could go through their invariable life. The famous foreign architects, who designed these large-scale public buildings for Beijing 2008 Olympic Games, are considered to declare the coming of the age of globalization in Chinese architecture design. The dreaming spaces will give people novel aesthetic experience with much of debate.

In the practice courses, we should also promote the architecture professional practice teaching reform by orienting on the needs of the enterprises, combining with engineering background, taking engineering technology as the main line. We should summarize the achievements of the practice teaching of architecture specialty and draw lessons from the successful experience of foreign countries. We strive to enhance the students' engineering accomplishment through close cooperation between universities and industry enterprises, which will cultivate 
students' engineering practice ability, engineering design ability and engineering innovation ability.

\section{Acknowledgement}

This research was financially supported by the Teaching And Research Project of Wuhan University Of Science And Technology (2013X051) and Year 2011 the "Twelfth Five Year Plan" of Educational Science in Hubei Province (2011B446) and Year 2011 Higher Education Teaching Research Project in Hubei Province (2011204)

\section{References}

[1] Ma Cheng- Song, Zhu Shi-Tan, Status quo architecture educational abroad and its inspiration to us, Journal of Architectural Education in Institutions of Higher Learning. vol. 31 (2004) no. 2, p. 30-32.

[2] Ni Qi, Wang Yi, Undergraduate Architecture Education for Kyushu University in Japan, Urbanism and Architecture, vol. 11 (2006) no. 5, p. 90-92 